\title{
Structural and optical properties of pure and Ag doped ZnO thin films obtained by sol gel spin coating technique
}

\author{
Syed Mansoor Ali ${ }^{1 *}$, W.A. FArooq ${ }^{1}$, M.R. BAig ${ }^{1}$, M.A. ShAR $^{2}$, M. Atif ${ }^{1}$, \\ S.S. AlGhamdi ${ }^{1}$, M.S. AlGarawi ${ }^{1}$, NAEem-UR-Rehman ${ }^{3}$, Muhammad Hammad Aziz $^{4}$ \\ ${ }^{1}$ Department of Physics and Astronomy, King Saud University, Riyadh, Saudi Arabia \\ ${ }^{2}$ Mechanical Engineering Department, College of Engineering, King Saud University, Riyadh, Saudi Arabia \\ ${ }^{3}$ National Centre for Nanotechnology, Department of Metallurgy and Materials Engineering, Pakistan Institute of Engineering \\ and Applied Sciences (PIEAS), Islamabad 45650, Pakistan \\ ${ }^{4}$ Department of Physics, College of Science, Az Zulfi, Majmaah University, Saudi Arabia
}

\begin{abstract}
We have investigated the influence of Ag doping on zinc oxide thin films. Pure and Ag doped, preferentially oriented transparent zinc oxide thin films were prepared by sol gel technique on a glass substrate using diethyl amine as a stabilizer. The X-ray diffraction analysis revealed that the films with hexagonal wurtzite type structure were polycrystalline in nature with a preferred grain orientation in the $\langle 101\rangle$ direction. The crystallite sizes decreased from $34 \mathrm{~nm}$ to $27 \mathrm{~nm}$ after silver doping. Both photoluminescence and optical transmission measurements showed that the band gap increased after the Ag doping. The structure and optical characterization studies clearly indicated the incorporation of $\mathrm{Ag}$ in $\mathrm{ZnO}$. Hence, the observed increase in the optical band gap and decrease in crystallite size can be directly attributed to the effect of $\mathrm{Ag}$ ion incorporation into the $\mathrm{ZnO}$ lattice.
\end{abstract}

Keywords: Ag doped ZnO; sol gel; structure properties; optical band gap; defects study

(C) Wroclaw University of Technology.

\section{Introduction}

Nanostructure semiconductor materials have a great importance due to their extraordinary physicochemical properties, which differ from their bulk counterparts. Zinc oxide $(\mathrm{ZnO})$ is one of the most attractive materials for developing the next generation of electronic and optoelectronic devices [1, 2], such as piezoelectric transducers, gas sensors, solar cell windows, short wavelength light emitting diodes, ultraviolet (UV) lasers, photodetectors, etc. [3-8], Zinc oxide ( $\mathrm{ZnO})$, a direct wide band gap n-type semiconductor $(3.4 \mathrm{eV}$ at room temperature), has a high exciton binding energy $(60 \mathrm{meV})$ [1]. It has a stable hexagonal wurtzite structure with lattice parameters $\mathrm{a}=$ $0.325 \mathrm{~nm}$ and $\mathrm{c}=0.521 \mathrm{~nm}$, and is composed of alternating planes with tetrahedrally-coordinated

*E-mail: mansoor_phys@yahoo.com
$\mathrm{O}^{2-}$ and $\mathrm{Zn}^{2+}$ ions, stacked alternately along the c-axis.

$\mathrm{ZnO}$ thin films have been prepared by different deposition techniques, such as pulsed laser deposition [9], r.f. sputtering [10], molecular beam epitaxy [11], electron beam evaporation [12], chemical vapor deposition [13] and spray pyrolysis [14]. In comparison to the other deposition techniques, the main advantages of sol-gel process are the excellent compositional control, homogeneous mixing of precursors on a molecular level and low crystallization temperature [15]. Commonly, the solgel technique for the preparation of $\mathrm{ZnO}$ thin films used a solvent of high boiling point, such as ethylene glycol and monoethanolamine. The $\mathrm{ZnO}$ films prepared by using these solvents were highly c-axis oriented [16-20]. On the other hand, c-axis oriented $\mathrm{ZnO}$ thin films were produced even at low temperature using a solvent of low boiling point, such as ethanol or isopropanol, and the crystal 
growth of the thin films was controlled by the temperature and heat treatment conditions [17, 18].

Silver is the most interesting among the metals because of its remarkable chemical reactivity in solution [21]. Therefore, it is very interesting to understand the role of silver in a transparent conducting oxide $\mathrm{ZnO}$ matrix during sol-gel synthesis. In this paper we report the effect of silver doping on the crystallization behavior, microstructure properties and optical properties of $\mathrm{ZnO}$ thin films prepared by a sol-gel process.

\section{Experimental}

The procedure for preparing pure and $\mathrm{Ag}$ doped $\mathrm{ZnO}$ thin films was as follows. First, a $0.25 \mathrm{M}$ solution of zinc acetate dehydrate $\left(\mathrm{Zn}\left(\mathrm{CH}_{3} \mathrm{COO}\right)_{2} \cdot 2 \mathrm{H}_{2} \mathrm{O}\right.$, Baker, $\left.99.9 \%\right)$ was dissolved in ethanol under magnetic stirring. After stirring the solution for about $20 \mathrm{~min}, 10$ drops of diethyl amine was added as a stabilizing agent and the mixture was further stirred for an hour at $60{ }^{\circ} \mathrm{C}$. For Ag doping, the silver nitrate $\left(\mathrm{AgNO}_{3}\right.$, Aldrich, $99.8 \%$ ) was chosen as a doping source. The films were deposited on a clean glass substrate by spincoating method. The spin coating speed and the deposition time were $3000 \mathrm{rpm}$ and $1 \mathrm{~min}$, respectively. After the spin coating process, the samples were dried at $100{ }^{\circ} \mathrm{C}$ for $5 \mathrm{~min}$ to evaporate the solvent and organic residuals. The process of spin coating and subsequent pre-heating treatment was repeated 10 times to obtain a desired thickness. At last, all the samples were annealed at $300{ }^{\circ} \mathrm{C}$ for an hour in air.

Crystallinity of the nanostructures was analyzed with a Bruker diffractometer (XRD) using the $\mathrm{CuK} \alpha$ radiation $(\lambda=1.5406 \AA)$. Optical transmission and reflectance of the thin films were studied with a JASCO (V-670) spectrophotometer. The photoluminescence was recorded at room temperature.

\section{Results and discussions}

The XRD patterns of pure and $\mathrm{Ag}$ doped $\mathrm{ZnO}$ thin film fabricated by sol-gel method on glass substrates are shown in Fig. 1. All the peaks of the $\mathrm{ZnO}$ thin films correspond to the peaks of standard ZnO (JCPDS Card No. S6-314). For both the samples, (100), (002) and (101) diffraction peaks are observed. In the XRD pattern, the growth of ZnO crystallites along (101) direction shows a preferential c-axis orientation. The doped films have higher and sharper diffraction peaks indicating an improvement in intensity with an increase in full width at half maximum (FWHM) of all the peaks as compared to pure $\mathrm{ZnO}$ film. The spectra show that the film has a polycrystalline structure, which is typical of a hexagonal wurtzite [19,20].

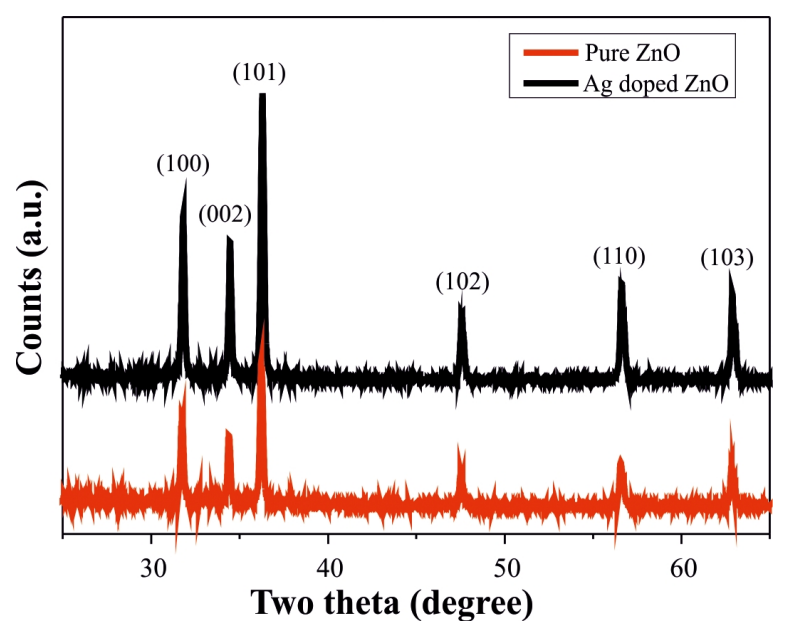

Fig. 1. XRD pattern of pure and $\mathrm{Ag}$ doped $\mathrm{ZnO}$ thin films on glass substrate.

In order to obtain detailed information about the structure, the crystallite size D along the c-axis was calculated according to the Scherrer equation [22]:

$$
D=\frac{0.9 \lambda}{\beta \cos \theta}
$$

where $\mathrm{D}$ is the crystallite size, $\lambda$ is the $\mathrm{X}$-ray wavelength $(\lambda=1.5406 \AA), \beta$ is the full width at halfmaximum (FWHM), and $\theta$ is the Bragg angle of (002) peak. The dislocation density ( $\delta$ ), defined as the length of dislocation lines per unit volume, is estimated using the equation [23]:

$$
\delta=\frac{1}{D^{2}}
$$

The lattice constants for the hexagonal structure of pure and doped thin films on glass substrates were 
determined from the following relations [24]:

$$
\frac{1}{d^{2}}=\frac{4}{3}\left[\frac{h^{2}+h k+k^{2}}{a^{2}}\right]+\frac{1}{c^{2}}
$$

where a, c are the lattice constants and h, k, 1 are the Miller indices of the planes, and $\mathrm{d}$ is the interplanar spacing. The $\mathrm{Zn}-\mathrm{O}$ bond length $\mathrm{L}$ is calculated by the following equation [25]:

$$
L=\sqrt{\frac{a^{2}}{3}+\left(\frac{1}{2}-u\right)^{2} c^{2}}
$$

where u parameter in the wurtzite structure is given by:

$$
u=\frac{a^{2}}{2 c^{2}}+0.25
$$

Due to the lattice mismatch between $\mathrm{ZnO}$ film and glass substrate, some stress can be produced during the deposition of $\mathrm{ZnO}$ thin films. Hence, the strain also significantly changes the structure and properties of $\mathrm{ZnO}$ films to some extent. For $\mathrm{ZnO}$ films with wurtzite structure, the strain can be obtained by the following formula [26]:

$$
\varepsilon=\frac{c-c_{o}}{c_{o}} \times 100 \%
$$

where $\varepsilon$ is the mean strain in $\mathrm{ZnO}$ thin films, $\mathrm{c}$ is the lattice constant of $\mathrm{ZnO}$ thin film, and $\mathrm{c}_{\mathrm{o}}$ is the lattice constant of bulk (standard $c_{o}=5.215 \AA$ ). The results calculated from the above equations are tabulated in Table 1.

The optical transmission spectra of pure and $\mathrm{Ag}$ doped $\mathrm{ZnO}$ thin films are shown in Fig. 2. The optical transmission of pure $\mathrm{ZnO}$ is about $87 \%$ in visible region and after doping it is increased to $89 \%$. A weak fluctuation in the spectra is due to interference phenomena in the thin film. As shown in Fig. 2, the UV band edge is blue shifted with doping of $\mathrm{Ag}$, indicating the broadening of the optical band gap.

For calculation of optical band gap energy (Eg) of the thin films, first we have assumed the absorption coefficient $\alpha=(1 / \mathrm{d}) \ln (1 / \mathrm{T})$, where $\mathrm{T}$ is the transmittance and $d$ is the film thickness. Hexagonal wurtzite structure $\mathrm{ZnO}$ has a direct band gap,

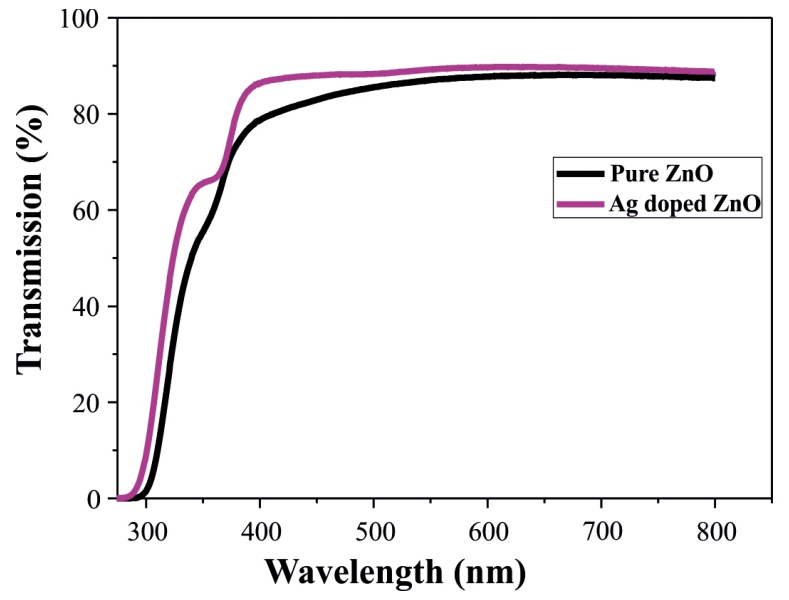

Fig. 2. Optical transmission spectra of pure and Ag doped $\mathrm{ZnO}$ thin films.

and the absorption edge for a direct band transition is given by [27]:

$$
(\alpha h v)^{2}=C(h v-E g)
$$

where $\mathrm{C}$ is a constant for a direct transition, $\mathrm{h}$ is Planck's constant, and $v$ is the frequency of the incident photon. Fig. 3 shows the graph of $(\alpha \mathrm{h} v)^{2}$ vs. photon energy hv (Tauc's plot) for pure and Ag doped $\mathrm{ZnO}$ thin films used for calculation of band gap. The linear part of $(\alpha \mathrm{h} v)^{2}$ versus hv at higher photon energies indicates that the pure and doped $\mathrm{ZnO}$ thin films have direct band transition. The linear portion of the curve, when extrapolated to zero, gives the optical band gap value.

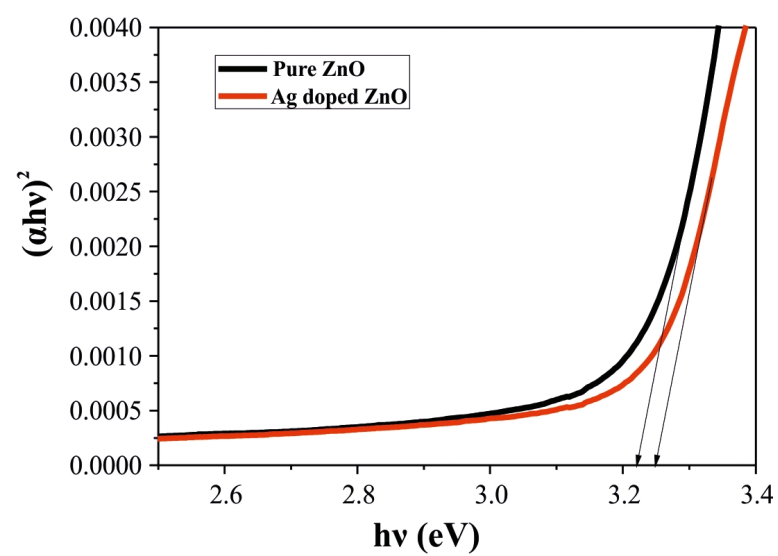

Fig. 3. Tauc's plot for calculation of band gap. 
From the results of Fig. 3, it can be seen that the energy band gap of the pure and doped $\mathrm{ZnO}$ thin films increased with the $\mathrm{Ag}$ doping. This increasing in the energy band gap is known as the Moss-Burstein shift [28]. Because of this, at high doping level in zinc oxide films, the donor electrons occupy the states at the lower edge of conduction band. Therefore, the optical band gap of Ag doped zinc oxide is greater than that of pure zinc oxide films.

The refractive index (n) is an important factor to fabricate the devices with good optical properties because the dispersion energy is dependent on to the optical transition and optical conductivity [29]. The value of refractive index for pure and $\mathrm{Ag}$ doped $\mathrm{ZnO}$ thin films were calculated by the equation 8 [30]:

$$
n=\sqrt{\frac{1+\sqrt{R}}{1-\sqrt{R}}}
$$

where $\mathrm{n}$ is the refractive index and $\mathrm{R}$ is the reflectance. The measured reflectances for pure and $\mathrm{Ag}$ doped $\mathrm{ZnO}$ thin films are shown in Fig. 4. The inset of Fig. 4 shows the variation of refractive index with the wavelength for pure and $\mathrm{Ag}$ doped $\mathrm{ZnO}$ thin films. It is observed that the refractive index $\mathrm{n}$ for both the films shows similar trend, sharply decreasing in the wavelength of 320 to 370 and then, after a sharp increase in the range of 370 to $450 \mathrm{~nm}$, the curve increases slowly with further increase of the wave length. It is also observed that the interference peak is shifted toward the longer wavelength as the Ag concentration increases.

The room temperature photoluminescence (PL) spectra of pure and Ag doped $\mathrm{ZnO}$ thin films emission spectra are shown in Fig. 5. There is one dominant band gap peak in the spectrum of pure $\mathrm{ZnO}$ at $411 \mathrm{~nm}$. However, in the $\mathrm{Ag}$ doped $\mathrm{ZnO}$ thin film this peak is shifted to $408 \mathrm{~nm}$, which confirms the increasing of band gap. It is also observed that two small peaks at 436 and $467 \mathrm{~nm}$ in pure $\mathrm{ZnO}$ disappear in $\mathrm{ZnO}$ doped with $\mathrm{Ag}$, where a new broad peak at $385 \mathrm{~nm}$ has developed. These peaks in pure and $\mathrm{Ag}$ doped $\mathrm{ZnO}$ films might be attributed to intrinsic defects, such as oxygen and zinc interstitials [30].

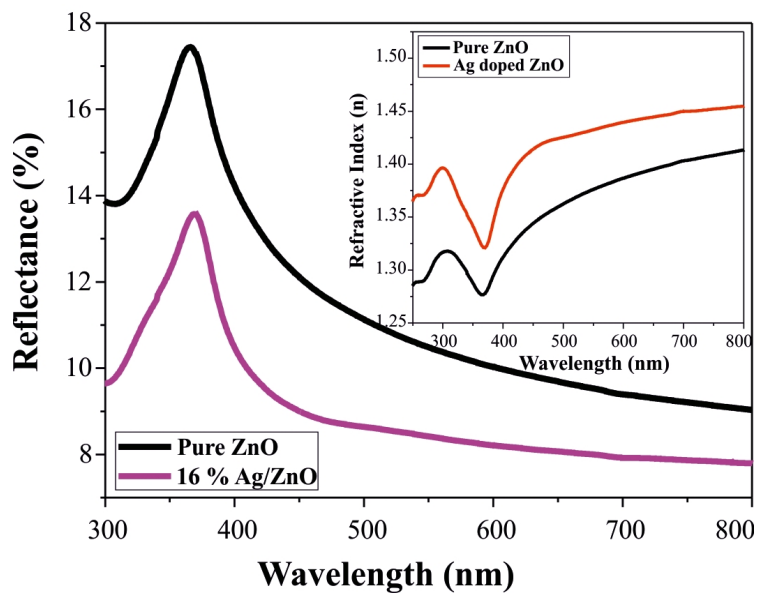

Fig. 4. Reflectance spectra of pure and $\mathrm{Ag}$ doped $\mathrm{ZnO}$ thin films.

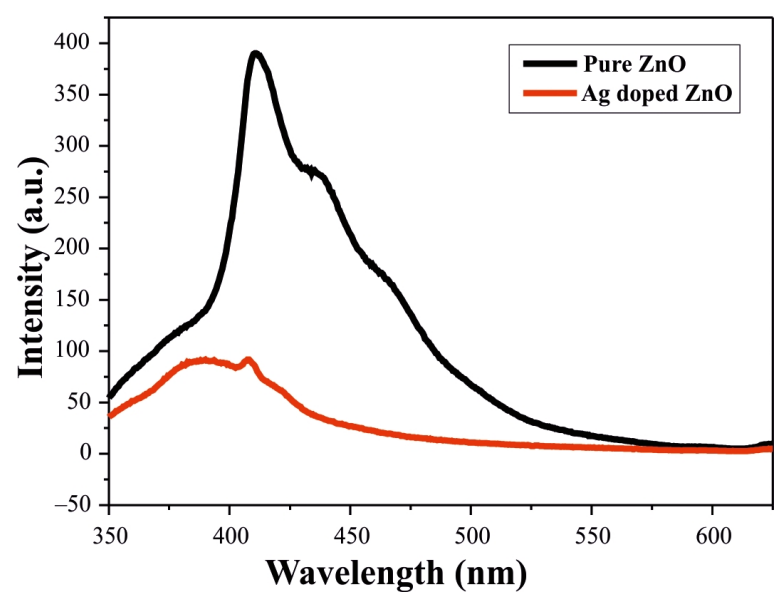

Fig. 5. Photoluminescence spectra of pure and Ag doped $\mathrm{ZnO}$ thin films.

\section{Conclusions}

Pure and $\mathrm{Ag}$ doped $\mathrm{ZnO}$ thin films were successfully prepared on glass substrates by sol-gel spin coating technique. The effects of Ag doping on the structural and optical properties of $\mathrm{ZnO}$ thin films were investigated. Pure and Ag doped deposited films are polycrystalline in nature and the crystallite size decreased with Ag doping. It was found that optical transmission and refractive index of $\mathrm{Ag}$ doped $\mathrm{ZnO}$ were higher than those of pure $\mathrm{ZnO}$ in the visible wavelength region. It was also observed that two small peaks at 436 and $467 \mathrm{~nm}$ in pure $\mathrm{ZnO}$ disappeared after $\mathrm{Ag}$ doping and a 
Table 1. Structural and optical parameters of pure and $\mathrm{Ag}$ doped $\mathrm{ZnO}$ thin films.

\begin{tabular}{|c|c|c|c|c|c|c|c|c|c|}
\hline \multirow{2}{*}{ Sample } & \multirow{2}{*}{$\begin{array}{c}\text { Crystallite } \\
\text { size D }(\AA)\end{array}$} & \multicolumn{2}{|c|}{ Lattice constant $(\AA)$} & \multirow{2}{*}{$\begin{array}{c}\text { Dislocation } \\
\delta \times 10^{14}\left(\text { lines } / \mathrm{m}^{2}\right) \\
\end{array}$} & \multirow{2}{*}{$\begin{array}{l}\text { Bond length } \\
\begin{array}{l}\mathrm{L}(\AA) \\
\end{array}\end{array}$} & \multirow{2}{*}{$\begin{array}{l}\text { Strain } \\
\varepsilon(\%) \\
\end{array}$} & \multirow{2}{*}{$\begin{array}{c}\text { Band gap } \\
(\mathrm{eV})\end{array}$} & \multirow{2}{*}{$\begin{array}{c}\text { Max. } \\
\text { transmission (\%) }\end{array}$} & \multirow{2}{*}{$\begin{array}{r}\text { Refractive } \\
\text { index } n \\
\end{array}$} \\
\hline & & $\mathrm{a}$ & $\mathrm{c}$ & & & & & & \\
\hline $\mathrm{Zn}$ & 345 & 3.256 & 5.221 & 8. & 8 & 0.1 & 3.217 & 88 & 1.40 \\
\hline doped $\mathrm{ZnO}$ & 280 & 3.259 & 5.228 & 12.75 & 1.951 & 0.2492 & 3.245 & 90 & 1.46 \\
\hline
\end{tabular}

new broad peak at $385 \mathrm{~nm}$ developed in the photoluminescence spectrum. These peaks in pure and $\mathrm{Ag}$ doped $\mathrm{ZnO}$ films might be attributed to intrinsic defects, such as oxygen and zinc interstitials.

\section{Acknowledgements}

The Authors would like to extend their sincere appreciation to the Deanship of Scientific Research at King Saud University for its funding of this research through the Research Group Project No. RGP-VPP-293.

\section{References}

[1] Klingshirn C., Phys. Status Solidi B, 71 (1975), 547.

[2] Tang Z.K., Wong G.K.L., Yu P., KawasaKi M., Ohtomo A., Koinuma H., Segawa Y., Appl. Phys. Lett., 72 (1998), 3270.

[3] Zhang T.C., Mei Z.X., Guo Y., Xue Q.K., Du X.L., J. Phys. D Appl. Phys., 42 (2009), 065303.

[4] Seow Z.L.S., Wong W.A.S., Thavasi V., Jose R., RAMAKRISHNA S., HO G.W., Nanotechnology, 20 (2009), 045604.

[5] Gupta T.K., J. Am. Ceram. Soc., 73 (1990), 1817.

[6] Saito S., Miyayama M., Koumot K., Yanagida H., J. Am. Ceram. Soc., 68 (1985), 40.

[7] Li Y.B., Bando Y., Golberg D., Appl. Phys. Lett., 84 (2004) 3603.

[8] Choopun S., Tubtimtae A., Santhaveesuk T., Nilphai S., Wongrat E., Hongsith N., Appl. Surf. Sci., 256 (2009), 998.

[9] Quaranta F., Valentini A., Rizzi F.R., J. Appl. Phys., 74 (1993), 247.

[10] Cracium V., Elders J., Gardeniers J.G.E., Appl. Phys. Lett., 65 (1994), 2963.

[11] Ong C.K., Wang S.J., Appl. Surf. Sci., 185 (2001), 47.

[12] Kuroyanagi A., Jpn. J. Appl. Phys., 28 (1989), 219.

[13] Natsume Y., SaKata H., Hirayama T., Yanagida H., J. Appl. Phys., 72 (9) (1992), 4203.
[14] Fiddes A.J.C., Durose K., Brinkman A.W., J. Cryst. Growth, 159 (1996), 210.

[15] Kavak H., Tuzemen E.S., Ozbayraktar L.N., ESEN R., Vacuum, 83 (2009), 540.

[16] Ohyama M., Kozuka H., Yoko T., Thin Solid Films, 306 (1997), 78.

[17] BaO D., Gu H., KuAng A., Thin Solid Films, 312 (1998), 37.

[18] Han H.C., Kim I.J., TaI W.P., Kim J.K., Shim M.S., SuH S.J., KIM Y.S., J. Korean Ceram. Soc., 40 (2003), 1113.

[19] Kim I.J., HaN H.C., LEE C.S., SONG Y.J., TAI W.P., SUH S.J., KIM Y.S., J. Korean Ceram. Soc., 41 (2004), 136.

[20] Wang Y., Chu B., Superlattice. Microst., 44 (2008), 54.

[21] Henglein A., J. Phys. Chem., 97 (1993), 5457.

[22] Rani S., Suri P., Shishodia P.K., Mehra R.M., Sol. Energ. Mat. Sol. C., 92 (2008), 1639.

[23] Wang X.S., Wu Z.C., Webb J.F., LiU Z.G., Appl. Phys. A-Mater, 77 (2003), 561.

[24] El-Kadry N., Ashour A., Mahmoud S.A., Thin Solid Films, 269 (1995), 112.

[25] Barret C.S., Massalski T.B., Structure of Metals, Pergamon Press, Oxford, 1980.

[26] Bahsi Z.B, Oral A.Y., Opt. Mater, 29 (2007), 672.

[27] Nishino J., Ohshio S., Kamata K., J. Am. Ceram. Soc., 75 (1992), 3469.

[28] Serpone N., Lawless D., Khairutdinov R., J. Phys. Chem., 99 (1995), 16646.

[29] Sernelius B.E., Berggren K.F., Jim Z.C., HamBerg I., Grandvist C.G., Phys. Rev. B, 37 (1988), 10244.

[30] Wu Q.H., Song J., Kang J., Dong Q.F., Wu S.T., Sun S.G., Mater. Lett., 61 (2007), 3679.

Received 2014-12-31 Accepted 2015-06-12 